\title{
Participación ciudadana en la creación de contenidos como herramienta de fidelización y consenso
}

\author{
Isaías Blázquez \\ Director de Contenidos Digitales en la radiotelevisión \\ pública de Castilla-La Mancha
}

\section{Referencia de este artículo}

Blázquez, Isaías (2021). Participación ciudadana en la creación de contenidos como herramienta de fidelización y consenso. En: adComunica. Revista Científica de Estrategias, Tendencias e Innovación en Comunicación, $\mathrm{n}^{\circ} 21$, 289-294. DOI: http://dx.doi.org/10.6035/2174-0992.2021.21.14

La sociedad avanza a un ritmo frenético en el uso de la tecnología, espoleada por los desarrollos vanguardistas de las multinacionales del sector. En ese escenario, los medios de comunicación públicos tratan de adaptarse sin perder de vista su razón de ser y sus objetivos empresariales. Sin embargo, están sometidos a estresantes transformaciones en sus organizaciones y en sus contenidos, en la manera de diseñarlos, ejecutarlos y dinamizarlos.

A través del contenido generado por usuario, los medios de comunicación estrechan lazos con sus usuarios y los fidelizan en torno a su marca. Este resultado puede ser determinante en la salvaguarda de la credibilidad de los medios de comunicación, al mantener una relación de confianza y transparencia con los ciudadanos. Un aspecto que para las radiotelevisiones públicas es trascendental, puesto que la cercanía y el servicio público son dos de los elementos que articulan su creación. Especialmente en un contexto de deformación de la realidad, en el que es creciente la amenaza de ruptura en el consenso sobre los hechos, según indican diversos autores.

Primero debemos entender el afán de las empresas de medios, privados y públicos, de mantener sus estructuras de consumo tradicional (radio, televisión, prensa) con las adaptaciones necesarias que requieren los tiempos presentes. Eso sí, al mismo tiempo desarrollan nuevas fórmulas y espacios tecnológicos para los ciudadanos, que cada vez se comportan más como usuarios que como consumidores al uso. 
Las resistencias económicas juegan un papel fundamental contra el cambio de paradigma, especialmente en el sector privado. El denominado duopolio televisivo, formado por Atresmedia y Mediaset, alcanzó hasta un 85,4\% del mercado publicitario, en un contexto en el que las caídas de publicidad en televisión llegaban al 40\% (Cano, 2017). En internet, la tarta se la reparten unas pocas multinacionales: Google tenía, en cifras estimadas, el control sobre más del 86\% de las búsquedas del mundo en 2018 y casi el 33\% de la publicidad digital (Fernández, 2018). El $40 \%$ de los internautas usas las redes sociales para acceder a la información, para el 27\% esta es la vía principal de acceso a noticias (Amoedo, 2020).

Se configura de esta manera una suerte de guerra fría entre entornos de consumo. Los operadores tradicionales compiten con las empresas tecnológicas por la atención del ciudadano. El rastro de datos que recogen de ellos es la clave de bóveda: servirá para que terceras empresas afinen con la publicidad que se sirve a esos ciudadanos. $\mathrm{Y}$ este es el sustento principal de estos modelos de negocio junto a los modelos de suscripción que se extienden en prensa (muros de pago) y en televisión (plataformas de contenido).

En medio de todo ello se encuentran los ciudadanos, cuya capacidad de participación en la creación de contenidos no tiene precedentes. Desde el surgimiento de las redes sociales tal y como hoy las conocemos y, en concreto, de plataformas como YouTube en 2005, los usuarios se lanzaron sin dudarlo a la creación de contenidos.

Se ha despertado una nueva generación de jóvenes innovadores de contenidos que tienen enfoques narrativos y visuales nuevos, orgánicos y eclécticos (Quintero, 2015: 138). Contar con ellos en el proceso de creación enriquece el resultado, pero también la dinámica creativa. En ocasiones, se convierten en el objetivo mismo del proceso, sin importar tanto el producto final como su involucración y alineamiento con unos valores determinados.

$\mathrm{Al}$ inicio del estado de alarma en marzo de 2020 en España y el confinamiento de la población, se generaron diversas iniciativas de creación compartida con los ciudadanos, sobre todo impulsadas desde los medios de comunicación públicos. Los usuarios, desde sus hogares, tuvieron la oportunidad de generar contenidos que reforzaron su sentimiento de pertenencia y comunidad. Una de esas iniciativas fue puesta en marcha para reforzar el acceso a los contenidos educativos por parte de los estudiantes que vieron detenidas sus clases. En Castilla-La Mancha, decenas de profesores y cientos de alumnos participaron en la difusión de vídeos generados por ellos mismos centrados en diversas temáticas educativas. Se trató de una iniciativa transmedia que se desarrolló en la plataforma digital de servicio público de la radiotelevisión autonómica, CMMPlay, así como en los canales tradicionales (televisión, radio) donde las creaciones tuvieron espacios de emisión semanales.

El contenido generado por usuario con un fin de utilidad y servicio público es una de las oportunidades que los medios de comunicación autonómicos pueden aprovechar. 
También la cercanía y la participación directa de los ciudadanos como herramienta de fidelización. La demarcación regional de estos medios les permite conocer mejor los intereses, inquietudes y necesidades de los ciudadanos. Una ventaja competitiva frente al consumo de contenidos universales que producen determinadas empresas privadas de medios de comunicación y de plataformas tecnológicas.

Algunos ejemplos de radiotelevisiones públicas sirven como prueba de que la relación con los usuarios ha alcanzado un nuevo nivel de intensidad. Al calor de entornos especializados como PlayZ en la búsqueda de públicos jóvenes, surgen en los últimos años desarrollos tecnológicos específicos y creación de equipos especializados en las radiotelevisiones públicas.

En octubre de 2018, Castilla-La Mancha Media presenta la primera OTT de una radiotelevisión pública centrada en contenidos de utilidad y de servicio público, con producciones propias y propiciando la generación de contenido por parte del usuario. Un mes antes, se lanza el proyecto Los Investigadores, una experiencia transmedia en diversos institutos que simula un escape room en el que se deben demostrar conocimientos adquiridos en las aulas. El proyecto tiene un importante componente de participación ciudadana, mediante la presentación y defensa de candidaturas, la superación de retos semanales, la votación en los programas y la participación en contenidos paralelos a la emisión en plataforma y en televisión.

El programa, galardonado con un Premio Iris de la Academia de Televisión, abrió la puerta a otras fórmulas de participación social en proyectos también didácticos como Aventura con Romanos y Aventura con Dinosaurios, ambos también en la plataforma y con una fuerte vocación transmedia en la radio y en la televisión públicas. A partir de ahí, la relación con los ciudadanos ya no volverá a ser la que fue. Los usuarios, con su capacidad para elegir qué contenidos consumir, cuándo, cómo, dónde y con quién, forman ya parte fundamental de la cadena de creación de contenidos. Su involucración en todo el proceso creativo acerca o aleja la posibilidad de que sean parte del contenido y de que aprovechen todas las oportunidades de conocimiento que en éste se proponen.

La utilidad del contenido de los medios de comunicación públicos es la médula espinal de su funcionamiento. La apuesta por la creación compartida genera una nueva dimensión de contenidos y de relación con los ciudadanos, empoderados por sus medios públicos a lo largo del proceso creativo. No obstante, no es posible obviar el peso del producto de dicha colaboración. Ese es el elemento de valor para el conjunto de la sociedad.

Así pues, la atención se sigue enfocando en el contenido y no en el dispositivo. El dispositivo es solo un medio para ver el contenido (Quintero, 2015: 144). Es en el contenido donde recae la relación entre broadcasters públicos y usuarios. Es el contenido el resultado de dicha comunión. Y es del contenido de donde los ciudadanos deben extraer la utilidad a la que se deben sus medios de comunicación públicos. 
Las radiotelevisiones públicas, a través de la participación ciudadana, son capaces no solo de trabajar por el desarrollo de sus sociedades, sino también de hacer frente a retos globales desde posiciones regionales.

Internet ha puesto en juego el consenso global sobre determinados hechos, una amenaza que la que afecta a la verdad (Mina, 2018). Ese «disenso digital» acuñado por la investigadora de la Universidad de Leeds Penny Andrews es el término que definiría esta nueva época en la que se generan con más facilitad cámaras de resonancia en internet en las que los ciudadanos terminan encerrados (Vartanian, 2019). Y para el filósofo Robert Talisse (2019), las personas tendemos a radicalizar nuestras creencias si solo nos relacionamos con quienes estamos de acuerdo o consumimos información que reafirman nuestras opiniones (Amorós, 2020: 249).

Los medios de comunicación públicos, y en concreto los servicios audiovisuales autonómicos, se configuran como actores fundamentales en la protección del consenso sobre los hechos. Este consenso sirve de base para la configuración de nuestras sociedades, pero sufre la amenaza de la desinformación, de las conspiraciones y de cualquier técnica de deformación de la realidad. «La victoria de la mentira es la derrota de la libertad. Cualquier forma de totalitarismo se sustenta en la distorsión o borrado de hechos y datos, y en el exterminio de la verdad» Quian (2020). Para el autor, las conspiraciones son una herramienta especialmente preocupante cuando «se convierten en narraciones históricas que pueden extenderse a través de la transmisión cultural».

Los servicios públicos deben ser capaces de generar confianza y certidumbre mediante la relación con los ciudadanos, fomentando el conocimiento a través del diálogo, la transparencia y la honestidad. Un ciudadano al que se le escucha, con quien se conversa y al que se le implica en el proceso creativo, es un activo para el servicio público y para la sociedad.

Los medios de comunicación públicos tienen una clara responsabilidad con los ciudadanos a los que sirven y con el futuro de las sociedades. Se trata de la protección de un sistema de confianza quebrado por la aplicación de viejas técnicas de polarización mediante nuevas herramientas cuyo poder y alcance no se pueden cuantificar. Estos servicios públicos audiovisuales pueden fomentar la generación de confianza a través de contenidos innovadores, honestos y comprometidos con sus ciudadanos. Quizá los sistemas de confianza «puede que vuelvan a tener otra oportunidad» (Magallón Rosa, 2020: 139) tras un período de incertidumbre, caos y tragedia como el que estamos viviendo. «La confianza, entendida como oportunidad, pero también como posibilidad».

Una posibilidad orbitando en medio de un big bang social, mediático y financiero que promete mantenerse en la década que comienza (Magallón Rosa, 2020: 139). En ese universo, las radiotelevisiones públicas tienen el reto de situar al ciudadano en el centro del esfuerzo de centenares de profesionales. A la participación en 
los contenidos como herramienta de fidelización de los usuarios. Y a los medios de comunicación públicos, como el escenario compartido para el desarrollo de las sociedades en un entorno de confianza y de consenso.

\section{Referencias}

Amoedo, Avelino (2020). Los algoritmos superan a la marca de los medios para llegar a las noticias en internet. Digital News Report. Consultado el 26 de diciembre de 2020 en: https://www.digitalnewsreport.es/2020/los-algoritmos-superan-ala-marca-de-los-medios-para-llegar-a-las-noticias-en-internet/

Amorós, Marc (2020). ¿Por qué las fake news nos joden la vida?. Madrid: LID Editorial.

Cano, Fernando (2017). Las televisiones autonómicas pierden 230 millones de euros en publicidad a favor del duopolio. El Español. Consultado el 26 de diciembre de 2020 en: https://www.elespanol.com/economia/empresas/20170614/223728628_0. html.

Fernández, Jorge (2018). (Inter)nacionalizar Facebook o un asunto crucial de política cultural. El País. Consultado el 26 de diciembre de 2020 en: https://blogs. elpais.com/alternativas/2018/04/internacionalizar-facebook-o-un-asunto-crucial-depol\%C3\%ADtica-cultural.html

Magallón Rosa, Raúl (2020). Desinformación y pandemia: la nueva realidad. Madrid: Ediciones Pirámide.

Mina, An Xiao (2018). Learning the politics of "digital dissensus". Civic Hall. Consultado el 26 de diciembre de 2020 en: https://civichall.org/civicist/learning-thepolitics-of-digital-dissensus/

Quian, Alberto (2020). Pandemia de mentiras sobre el coronavirus: así amenaza nuestra salud y la democracia. Ctxt. Consultado el 26 de diciembre de 2020 en: https://ctxt.es/es/20200401/Politica/31843/bulos-redes-fake-news-democraciapandemia-covid-conspiranoicos-alberto-quian-infodemia.htm

Quintero, Marlon (2015). Innovación en la creación de contenidos para medios: Herramientas y estrategias para generar contenidos exitosos. Boca Raton: J. Ross Publishing.

Talisse, Robert B. (2019). Overdoing democracy. Why we must put politics in its place. Nueva York: Oxford Universty Press.

Vartanian, Hrag (2019). Required Reading. Hyperallergic. Consultado el 26 de diciembre de 2020 en: https://hyperallergic.com/479449/required-reading-407/ 
